\title{
Incidence of postoperative vomiting in pediatric population undergoing anesthesia: a prospective cohort study
}

\section{Incidencia de vómito postopera torio en población pediátrica sometida a anestesia: estudio de cohorte prospectiva}

\author{
María Fernanda Jaimes Daza ${ }^{(\mathbb{D}}$, Ismael Enrique Alarcón Tarazona ${ }^{a}$ (D), Jonathan Alexis Duarte \\ Villamizar ${ }^{b}$, Héctor Julio Meléndez ${ }^{b}$, Héctor Hugo Torres ${ }^{b}$ \\ ${ }^{a}$ Medical students, Universidad Industrial de Santander. Bucaramanga, Colombia. \\ ${ }^{\mathrm{b}}$ School of Medicine, Anesthesia and Resuscitation Department, Universidad Industrial de Santander. Bucaramanga, Colombia.
}

Correspondencia: Calle 20 \# 26-44, Edificio Treviso. Bucaramanga, Colombia. E-mail: mafejada97@gmail.com

\section{Abstract}

What do we know about this problem?

Postoperative nausea and vomiting are frequent postoperative adverse effects associated with anesthesia and/ or surgery, and they have a negative impact on patient wellbeing, care quality and costs. Although this problem is greater in the pediatric population, its frequency is underestimated because of assessment challenges associated with the biopsychosocial characteristics of this population group.

What is the contribution of this study?

The ability to gauge the size of the problem in our population and to identify the factors associated with postoperative vomiting will contribute to adequate risk stratification and to ensure the use of prophylactic therapies and preventive interventions consistent with the characteristics of each population group.

\section{How to cite this article}

Jaimes Daza MF, Alarcón Tarazona IE, Duarte Villamizar JA, Meléndez H], Torres $\mathrm{HH}$. Incidence of postoperative vomiting in pediatric population undergoing anesthesia: a prospective cohort study. Colombian Journal of Anesthesiology. 2020;48(4):e932.

\section{Introduction}

Postoperative nausea and vomiting are frequent adverse effects of anesthesia and surgery. Impact is greater in pediatric populations compared to adults and the reported incidences are heterogeneous.

\section{Objective}

To describe the incidence of postoperative vomiting in a pediatric population and to identify associated risk factors.

\section{Materials and methods}

This prospective cohort study included 190 children aged 3 to 12 years undergoing surgery and anesthesia in a maternal and child health clinic in Bucaramanga (Colombia). The main outcome variable was postoperative vomiting. Data were analyzed using bivariate, multivariate analysis and logistic regression to assess the associated risk factors.

\section{Results}

The overall incidence of postoperative vomiting was $18.95 \%(95 \% \mathrm{Cl}: 13.32-24.57)$, with a higher incidence at home vs. hospital ( $12.63 \%$ vs. $9.47 \%$ ). After adjustment, associated risk factors were anesthesia time longer than 45 minutes (OR: 2.33; $95 \% \mathrm{Cl}: 1.10-4.90$ ) and postoperative use of opioids (OR: $4.17 ; 95 \%$ IC: 1.65 10.5). The incidence of postoperative vomiting was higher in patients who underwent emergency surgery.

\section{Conclusion}

This is the first study in Colombia that evaluates the incidence of postoperative vomiting in children. The incidence in our pediatric population is within the ranges reported worldwide. Associated risk factors were anesthesia time longer than 45 minutes and postoperative use of opioids. Further research is required in order to study emergency surgery as a potential risk factor.

\section{Keywords}

Postoperative nausea and vomiting; anesthesia; pediatrics; postoperative complications; surgery. 


\section{¿Qué sabemos acerca de este}

\section{problema?}

Las náuseas y vómito postoperatorio son resultados adversos frecuentes derivados del acto anestésico y/o quirúrgico, que impactan de manera negativa sobre el bienestar del paciente, la calidad del servicio y sus costos. La magnitud de este problema es mayor en la población pediátrica y su frecuencia es subestimada por la dificultad para su evaluación dadas las características biopsicosociales de este grupo poblacional.

\section{¿Quéaporta este estudio de nuevo?}

Conocer la magnitud del problema en nuestra población e identificar los factores asociados a vómito postoperatorio permiten realizar una adecuada estratificación del riesgo y brinda las herramientas para garantizar terapias profilácticas e intervenciones preventivas acordes con las características de cada grupo poblacional.

\section{Resumen}

\section{Introducción}

Las náuseas y el vómito postoperatorios son un resultado adverso frecuente derivado del acto anestésico y/o quirúrgico. La magnitud de este problema es mayor en la población pediátrica en comparación con la población adulta, con una considerable heterogeneidad de datos respecto a la incidencia.

\section{Objetivo}

Describir la incidencia de vómito postoperatorio en población pediátrica y sus factores de riesgo asociados.

\section{Materiales y métodos}

Estudio de cohorte prospectivo realizado en Clínica Materno Infantil de III-IV nivel de Bucaramanga (Colombia), en 190 pacientes pediátricos con edades entre 3 y 12 años, sometidos a cirugía sin discriminar técnica anestésica. Se realizó análisis bivariado, multivariado y regresión logística.

\section{Resultados}

La incidencia de vómito postoperatorio en el estudio fue de 18,95 \% (IC-95 \% [13,32-24,57]), y es mayor en la casa que en la institución hospitalaria ( $12,63 \%$ vs. 9,47\%). Tras el ajuste, los factores de riesgo establecidos fueron el tiempo anestésico mayor de 45 minutos (OR 2,33; IC-95 \% [1,10-4,90]) y uso de opioide postoperatorio (OR 4,17; IC-95 \% [1,65-10,5]). Hubo una incidencia importante de vómito postoperatorio en pacientes sometidos a cirugía de urgencias.

\section{Conclusiones}

Este es el primer estudio en Colombia que evalúa la incidencia de vómito postoperatorio en población pediátrica. La incidencia se encuentra dentro del rango reportado en la literatura mundial y se establecieron como factores asociados el tiempo anestésico mayor a 45 minutos y uso de opioides en el postoperatorio. Consideramos que debe estudiarse la cirugía de urgencias como posible factor de riesgo en estudios posteriores.

\section{Palabras clave}

Náusea y vómito postoperatorio; anestesia; pediatría; complicaciones posoperatorias; cirugía.

\section{INTRODUCTION}

Perioperative medicine as the area in charge of providing comprehensive care to surgical patients continues to evolve. However, postoperative vomiting (POV) as one of the complications associated with anesthesia stands out as a frequent adverse outcome causing a negative impact on patient wellbeing, quality and cost (1).

Because of its characteristics, the pediatric population is highly prone to developing this undesirable outcome, with an incidence ranging between $7.3 \%$ (2) and $82 \%(3)$, twice as high as in the adult population. (4)

This high prevalence is compounded by a challenging assessment due to communication problems inherent to this population group, resulting in lower accuracy and veracity of the data available regarding the size of this problem.

In clinical practice, POV is one of the main causes of dissatisfaction and the primary cause of unexpected hospital readmissions $\underline{(5,6)}$. Its clinical implications include difficulty initiating oral intake of food and medications, dehydration, electrolytic imbalances, aspiration, and unfavorable surgical outcomes such as suture dehiscense, bleeding or hematoma formation (7-9). In turn, these have a negative effect on quality indicators and healthcare costs. It is estimated that every nausea and vomiting episode increases hospital length of stay by 29 minutes (10) and that dissatisfaction is such that patients would be willing to pay additional costs in order to prevent their occurrence $\underline{(11)}$.

Different risk factors for POV have been described. They have been classified as inherent to the patient, the anesthetic technique and the type of surgery. In terms of patient characteristics, a linear increase in incidence has been observed after 3 years of age through puberty, with no gender differences before adolescence (7). Moreover, an association has been shown between POV and genetic polymorphisms located on muscarinic and dopaminergic receptors, which explains high individual susceptibility (12). Kinetosis and a family history of POV are independent risk factors, and some studies mention separation anxiety as another element associated with a higher incidence of POV, albeit with a not strong relationship (13). In terms of the 
anesthetic technique, opioid use doubles the risk of POV, while inhaled anesthetics are associated with increased incidence, particularly in children identified as prone to developing this complication (7). Certain procedures such as strabismus surgery, tonsillectomy, tympanoplasty, and procedures lasting $>30$ minutes, have been shown to increase the occurrence of POV in children $(9,11)$.

Pharmacological and non-pharmacological resources can be used for the prevention and control of POV in children. Pharmacological approaches include $5 \mathrm{HT}_{3}$ receptor antagonists, dexamethasone, metoclopramide, dimenhydrinate and droperidol (7). These drugs can be used as monotherapy, but it has been shown that their effectiveness increases when administered as combined therapy, which is recommended particularly in children with a risk of $30 \%$ or more. Monotherapy is recommended when the risk is $20-25 \%$, and no type of prophylaxis is recommended when the risk is under $15 \%$ (9). Other drugs such as neurokinin 1 (NK1) receptor antagonists (e.g., aprepitant and fosaprepitant) have been successfully tried in post-chemotherapy vomiting with favorable results. Data support their safety in the pediatric population (14), and there is evidence of similar effects to those of ondansetron in the prevention of POV in adults (15). On the other hand, non-pharmacological treatments like P6 stimulation with different acupuncture techniques have shown to reduce POV substantially, with effects similar to those of some antiemetics like ondansetron, droperidol and metoclopramide (11).

The objective of this study is to describe the incidence of postoperative vomiting in the pediatric population and to assess potential risk factors and their degree of association with POV. This will serve as a basis for the implementation of timely prevention and treatment strategies designed to reduce length of stay, parent dissatisfaction and complications, while improving quality standards.

\section{MATERIALS AND METHODS}

Observational cohort study conducted between July and September, 2018 in pediatric patients aged 3 to 12 years taken to any type of surgery at the San Luis level IIIIV mother-and-child clinic in Bucaramanga (Colombia), without discriminating by anesthetic technique. This study was approved by the following two ethics committees: 1. Committee of Ethics in Scientific Research of the Universidad Industrial de Santander (CIENCI-UIS), in a meeting held on December 15, 2017, as recorded in act number 29. 2. Hospital Bioethics Committee of the Materno Infantil San Luis Clinic, in its session of June 21, 2018, as recorded in act number DM-77-18.

Cases were gathered while the patients were in the preoperative room. The informed consent, past history and sociodemographic data were collected at that time. Variables pertaining to the surgery and the anesthetic technique were gathered later from the surgical notes and the anesthesia record. Finally, followup was conducted 24 hours after surgery, with telephone follow-up for patients who had already been discharged. All data were entered by trained staff in a tool designed for that purpose. Additionally, data collection was supervised and weekly verification of the information was performed before entering the data into the database.

Patients lost to follow-up, patients on chemotherapy, in the pediatric intensive care unit and/or on mechanical ventilation, and patients with a surgical condition manifesting with nausea and vomiting (e.g., appendicitis, bowel obstruction, etc.) were excluded.

The dependent variable was postoperative vomiting and its frequency, understood as forceful ejection of gastric contents from the mouth witnessed by the medical or nursing staff, or reported by the guardian during the postoperative period; the postoperative period was defined as the 24-hour period starting immediately after the surgical procedure was completed. The independent variables included a past history of kinetosis, past history of POV, type of surgery (urgent or elective), procedure performed, surgical and anesthesia time, anesthetic agent used, use of adjunct medications, need for muscle relaxation reversion and dose, use of antiemetic prophylaxis and drug used, use of postoperative opioid analgesia and type of opioid used, need for rescue antiemetic agent during postoperative care. No information on nausea was gathered due to difficult assessment of this variable in the study population as a result of limited communication in some of the patients.

Calculation of sample size was based on reported incidences of postoperative nausea and vomiting ranging between 7.3 (2) and $82 \%$ (3) according to prior studies carried out in the world. In order to find a $25 \%$ incidence of POV as the mean value in all the studies, a sample size of 155 participants was required, with a $15 \%$ attrition, for a final size of 179 patients, a power of $80 \%$ and a $5 \%$ alfa or precision error with two-tail hypothesis, calculated using the Epidat 3.1 software package.

Data were entered in duplicate in an Excel database and were then verified and finally filtered until a single database was obtained. Patients lost to follow-up were not included in the analysis. The clinical characteristics of the patients were described using means and proportions with their respective $95 \%$ confidence interval $(95 \% \mathrm{Cl})$. Fisher's exact test and the t-test with a 0.05 significance were used to assess differences between dichotomous and continuous variables, respectively. Absolute risk (AR) with its $95 \% \mathrm{Cl}$ was used to assess incidence, and relative risk (RR) with its respective $95 \%$ confidence interval was used to assess potential risk factors. A bivariate analysis was performed, calculating RR as impact measure, with statistically significant differences assumed to be those in which the $p$ value was less than 0.05 . Stratifications were made to control for confounding variables applying the MantelHaenszel chi-square, raw and adjusted RR was assessed and RR was also assessed for each of the variables to determine any effect modifications. A multivariate analysis was performed followed by step-by-step logistic regression, including all variables that showed significance in the bivariate analysis with $p \leq 0.20$, as well as those with biological plausibility. Data were analyzed using the STATA 14 software package. 
FICURE 1. Patient flow chart.

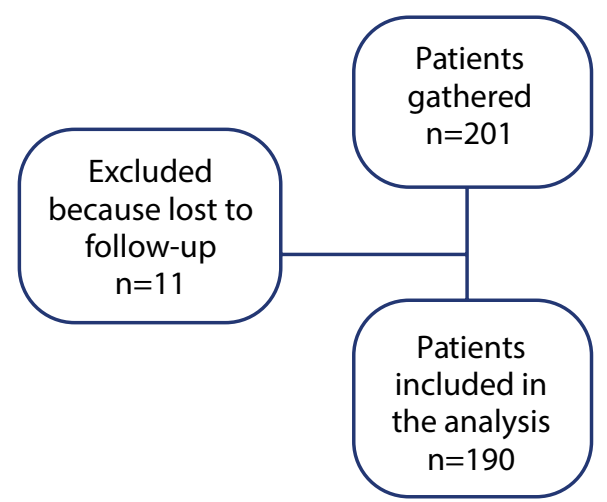

SOURCE: Authors.

\section{RESULTS}

In this study, 201 subjects were screened, and 11 were excluded as they were lost to follow-up (Figure 1). Of 190 patients included in the analysis, $65.79 \%$ were females, and mean age was 6.92 years (SD: 2.97 years). Antiemetic prophylaxis was given to $75.26 \%$ of the patients, with dexamethasone being the most commonly used medication $(73.16 \%)$. In terms of the surgical procedure performed, $13.68 \%$ were emergent surgeries and, of those, $76.92 \%$ were fracture reductions and $23.08 \%$ were various minor procedures such as abscess drainage and foreign body removal, among others (Table 1 ).

Urologic surgery was the most frequent and balanced general anesthesia was the most commonly usted technique. The variables described in the scales by Eberhart et al. (13) and Bourdaud et al. (1) were used to discriminate high-risk patients for POV; the use of antiemetic prophylaxis was assessed in this group, and it was found to be $80.47 \%$ in average (Table 1).

The incidence or absolute risk (AR) of the outcome variable (POV at 24 hours) was $18.94 \%$. A 24-hour followup was carried out as proposed in the protocol, and two incidence values were documented: POV in the hospital and at home. The latter was greater and significant when compared with inhospital POV $(p=0,029)$. When incidence was assessed by age group, it was higher in the group 7-9 years (23.91\%), but with no difference among groups. Urgent surgery and balanced anesthesia were associated with a high incidence of POV; however, there were no statistically significant differences either, a finding that will be a subject for discussion (Table 2).

Although antiemetic prophylaxis was used in $80 \%$ of patients in high risk groups, the incidence was very similar to that of the general population, with an average of $20.16 \%$. Antiemetic rescue was used in $37.5 \%$ of patients with POV in the hospital and in $4.17 \%$ of patients who had vomiting outside the hospital (Tables 1 and 2).

To assess the existence of associations between POV and potential risk factors, a bivariate analysis was initially conducted in which the variables showing high risk were: urgent surgery (RR: 2.31), surgical time $>30$ minutes (RR: 0.80 ), anesthesia time $>45$ minutes (RR: 2.73) and postoperative opioid use (RR: 2.79) (Figure 2).

FIGURE 2. Postoperative vomiting bivariate analysis.

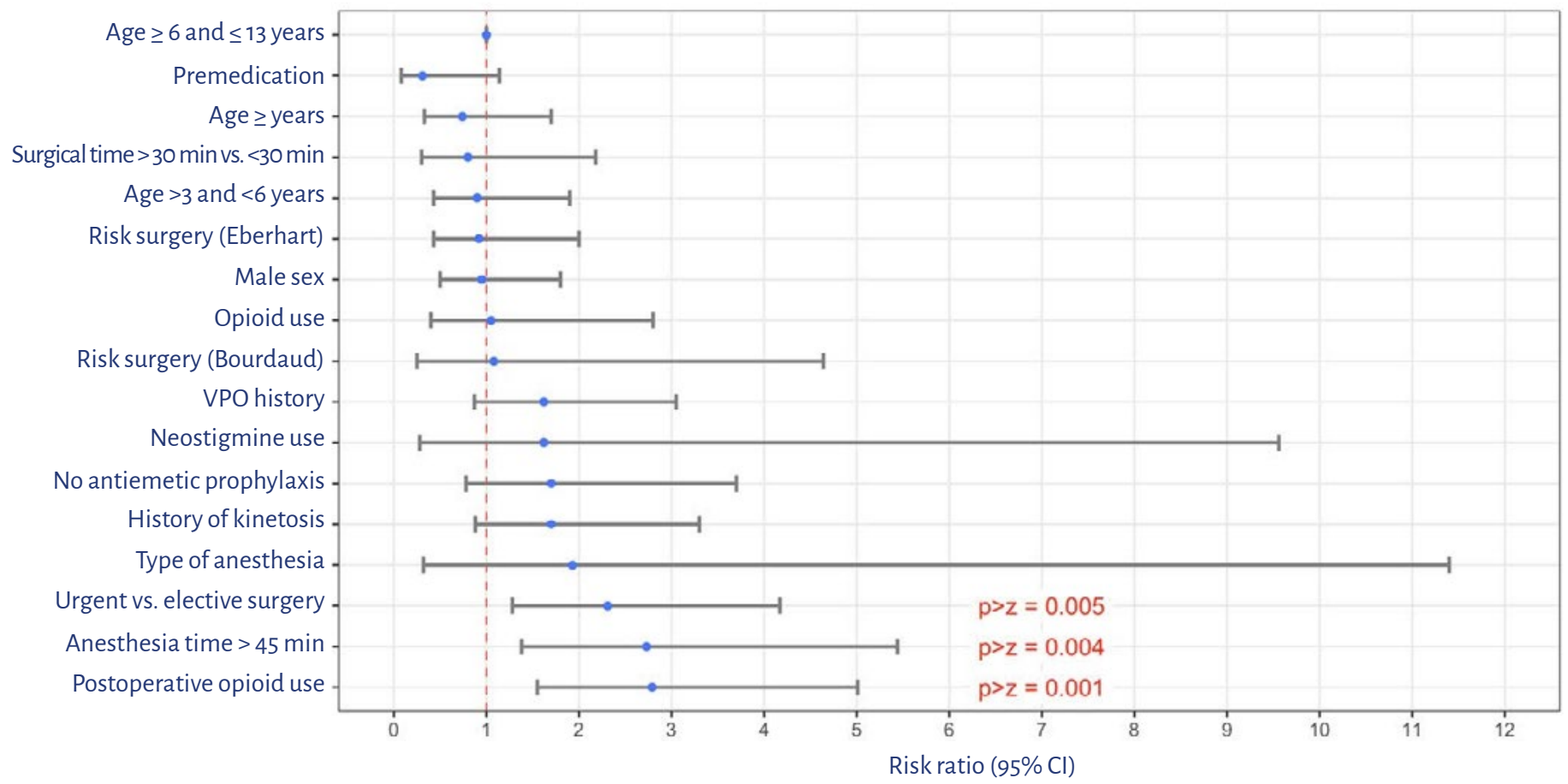

POV: postoperative vomiting. SouRCE: Authors. 
This was followed by a multivariate analysis and step-by-step logistic regression including all the variables that showed significant values of $p \leq 0.20$ in the bivariate analysis, as well as those that could have biological plausibility (Table 3). The only variables that were included in the final model as risk factors for POV were anesthesia time $>45$ minutes and postoperative opioid use. Coodness of fit of the model was 0.5492 (Table 4).

\section{DISCUSSION}

This study is the first to be performed in Colombia with the aim of determining the incidence of postoperative vomiting in the pediatric population aged 3 to 12 years. The incidence of POV was $18.95 \%$, very similar to the $18 \%$ incidence reported by Ali et al. in a retrospective study of 1079 children $\underline{16}$. These values are within the range described in the literature of $7.3 \%$ (2) to $82 \%$ (3). The intermediate value found in this study could be explained by the heterogenous sample in which the representation of patients with high-risk surgery such as strabismus, tonsillectomy and tympanoplasty was low (17). Another explanation for the finding of this incidence is the sample size calculated on the basis of the incidence reported in the world literature and not on each risk factor; although this would have been ideal, the main objective of the study was to describe overall incidence.

Moreover, it was a small sample size for estimating confidence intervals in the logistic regression model. Ideally - and this is a recommendation for future research sample size should be calculated based on associative models (18-20).

Past history of kinetosis and POV has been documented as a risk factor for the development of this event in the pediatric population (21). The frequency for these two factors was high in our study population (kinetosis $20.53 \%$ and POV $23.16 \%$ ); however, they were not included in the final logistic regression model possibly due to lack of power (sample size) $\underline{(22,23)}$.
TABLE 1. General patient characteristics.

\begin{tabular}{|c|c|}
\hline Variable & Mean \\
\hline Age (years) & $6.91(2.97)$ \\
\hline Surgical time (minutes) & $30(25-50)$ \\
\hline Anesthesia time (minutes) & $37(32-60)$ \\
\hline Gender & Frecuence (\%) \\
\hline Male & $65(43.21)$ \\
\hline Female & $125(65.79)$ \\
\hline \multicolumn{2}{|l|}{ Antiemetic prophylaxis } \\
\hline Dexamethasone & $139(73.16)$ \\
\hline Ondansetron & $1(0.53)$ \\
\hline Haloperidol & $1(0.53)$ \\
\hline Dexamethasone + ondansetron & $2(1.05)$ \\
\hline Total prophylaxis & $143(75.26)$ \\
\hline \multicolumn{2}{|l|}{ Past history and type of surgery } \\
\hline History of kinetosis & $39(20.53)$ \\
\hline History of POV & $44(23.16)$ \\
\hline Urgent surgery & $26(13.68)$ \\
\hline Elective surgery & $164(86.32)$ \\
\hline \multicolumn{2}{|l|}{ Type of surgery } \\
\hline Urologic & $60(31.58)$ \\
\hline Hernia repair & $47(24.74)$ \\
\hline Orthopedic & $43(22.63)$ \\
\hline Other & $22(11.58)$ \\
\hline Otolaryngological & $7(3.68)$ \\
\hline Endoscopic & $6(3.16)$ \\
\hline Laparoscopic & $3(1.58)$ \\
\hline Oncologic & $2(1.05)$ \\
\hline \multicolumn{2}{|l|}{ Type of anesthesia } \\
\hline Inhaled & $10(5.26)$ \\
\hline Balanced & $180(94.74)$ \\
\hline Opioid use $>30$ minutes & $27(75)$ \\
\hline Prophylaxis in surgery lasting more than 30 minutes & $22(18.49)$ \\
\hline Use of opioids in general & $163(85.79)$ \\
\hline \multicolumn{2}{|l|}{ Prophylaxis in high risk patients } \\
\hline Surgical time longer than $30 \mathrm{~min}$ & $120(77.92)$ \\
\hline Opioid use during surgery for more than $30 \mathrm{~min}$ & $21(77.8)$ \\
\hline Otolaryngological surgery & $6(85.71)$ \\
\hline
\end{tabular}

POV: Postoperative vomiting. SOURCE. Authors. 
TABLE 2. Absolute risk of postoperative vomiting.

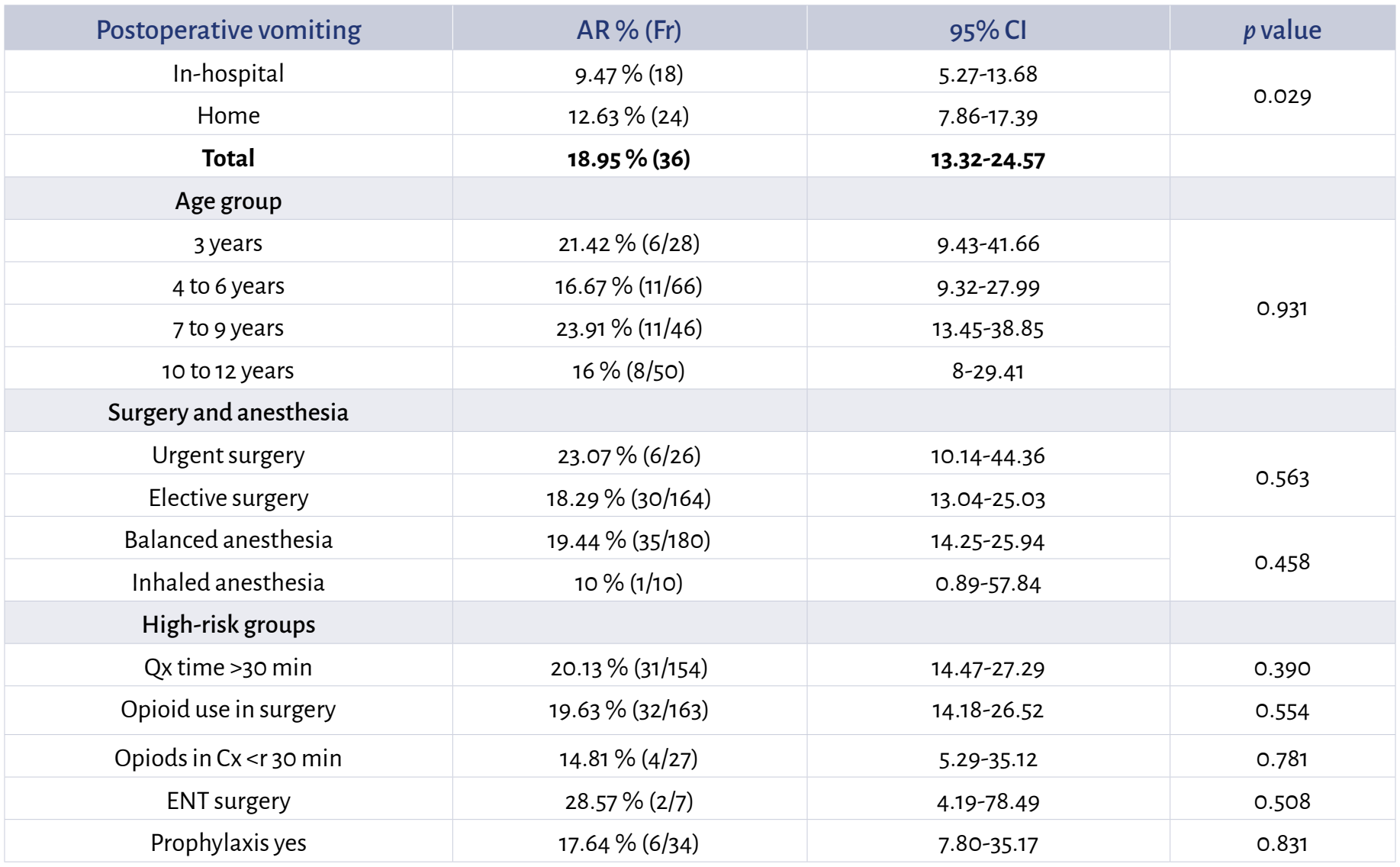

AR: absolute risk, $\mathrm{Cl}$ : confidence interval, Cx: surgery, ENT: otolaryngology, Fr: frequency, Qx: surgical. SouRCE: Authors.

TABLE 3. Logistic regression for postoperative vomiting.

\begin{tabular}{|c|c|c|c|}
\hline POP vomiting & RR & p value & $95 \% \mathrm{Cl}$ \\
\hline POP opioid use & 2.43 & 0.001 & $1.46-4.01$ \\
\hline Anesthesia time $>45$ min & 2.40 & 0.002 & $1.38-4.17$ \\
\hline Urgent surgery & 2.38 & 0.011 & $1.22-4.63$ \\
\hline Prophylaxis administration & 1.99 & 0.012 & $1.16-3.43$ \\
\hline History of kinetosis & 1.75 & 0.041 & $1.02-2.99$ \\
\hline Premedication administration & 0.32 & 0.062 & $0.09-1.05$ \\
\hline Intraoperative opioid use & 0.88 & 0.728 & $0.44-1.75$ \\
\hline
\end{tabular}

$\mathrm{Cl}$ : Confidence interval, POP: postoperative, RR: Relative risk. SourCE: Authors.

TABLE 4. Final model for postoperative vomiting.

\begin{tabular}{|c|c|c|}
\hline Variable & OR & $95 \% \mathrm{Cl}$ \\
\hline Anesthesia time $>45 \mathrm{~min}$ & 2.33 & $1.10-4.90$ \\
\hline POP opioid for analgesia & 4.17 & $1.65-10.5$ \\
\hline
\end{tabular}

$\mathrm{Cl}$ : Confidence interval, OR: Odds ratio, POP: postoperative. SouRCE: Authors. 
The use of antiemetic prophylaxis in high risk populations has been shown to be effective for several medications including high-dose fluids, ondansetron and dexamethasone $(3,6,24)$. In this study, antiemetic prophylaxis was used in $75.26 \%$ of the subjects, with dexamethasone being the most widely used medication in $73.16 \%$. Also, adherence to antiemetic prophylaxis in high risk surgeries (surgeries lasting > 30 minutes, otolaryngological procedures or prolonged opioid use) was high, ranging between 77 and $86 \%$. The incidence of POV in this group was similar to the general population, which may indicate some degree of effectiveness of antiemetic prophylaxis. It might be that if POV risk stratification scales are implemented and antiemetic medications are used according to protocols based on the established recommendations, incidence could be reduced substantially (11). Low prophylaxis effectiveness could also be explained by the antiemetic dose used. Czarnetzki et al. (25) found that the dose of dexamethasone is key in ensuring effectiveness, but this variable was not analyzed in this study and there is no information as to whether the described effective dose of $0.15 \mathrm{mg} / \mathrm{kg}$ up to a maximum of $4 \mathrm{mg}$ was used (26).

The type of surgery, mainly otolaryngological (ENT) and strabismus surgery, has been described as a risk factor for POV $(24,25)$. In this study, there were no cases of strabismus surgery and ENT procedures accounted for a very low proportion (3.68\%), which may explain that the lack of statistical significance when associating these procedures as risk factors is due mainly to the lack of power.

Urgent surgery and balanced anesthesia were associated with a high incidence of POV; however, there were no statistically significant differences. It is not clear why urgent surgery appears to increase the risk of POV, and since this study was not designed to answer that question, no variables that could be used to assess causality of this association were collected. The fact that patients undergoing urgent surgery are given opioids and NSAIDs for analgesia before entering the operating room and these agents have been shown to stimulate the chemoreceptor area for vomiting might be a potential explanation (9); however, new studies are required to assess variables that predispose to POV in patients undergoing urgent surgery.

It is important to highlight that, so far, urgent surgery has not been described as a risk factor for POV and our study lacks sufficient statistical power to confirm this association, considering that the sample size was not calculated based on risk factors, and the population was very heterogenous. On the other hand, although it is clear that inhaled anesthesia and, therefore, balanced anesthesia, is a trigger of POV and $94.47 \%$ of the patients in this study received this type of anesthesia, this variable did not reach statistical significance, as mentioned above. Moreover, antiemetic prophylaxis with single inhaled and/or balanced inhaled anesthetic agent reduces the risk of POV and it is similar to the use of total intravenous anesthesia as evidenced in a systematic review by Schaefer et al. (27). Besides being a source of bias, this points to the need for further studies with an important representation of total intravenous anesthesia and regional anesthesia.

Intra-operative opioids, considered a risk factor for POV in previous studies $(1,28)$, were used in $75 \%$ of cases. In contrast with the findings by Efune et al. (28) of an association and a greater reported use of long-acting opioids, this study did not find an association with the risk of POV. Similar to the findings by Efune, opioid administration as postoperative analgesic therapy in this study had a significant association with an increased risk of POV. It is worth noting that sample size in the study by Efune was large (1041 patients) and, unlike this study, it included only outpatients.

Anesthesia time was shown to be an independent risk factor for POV. Patients with anesthesia time longer than 45 minutes were 2.33 times more likely to develop POV than patients with shorter anesthesia time, and this is consistent with previous results reported by Bourdaud et al. (1), in which this variable had a statistically significant association with a 1.44 greater probability of POV and, consequently, was included in the risk prediction score proposed by the author. These results are also consistent with the description by Sinclair et al. (29), in which anesthesia time longer than 30 minutes increases the probability of vomiting by $59 \%$. In contrast, Kocaturk et al. and Efune et al. 28,30$)$ did not find an association between anesthesia time and the endpoint of interest. In another reference study, Eberhart et al. (13) describe surgical time $>30$ minutes as an independent risk factor for POV, a variable that was not found to have an association in this study. Because of the wide variability of the reported data, as described above, the debate is still open on whether predisposition to POV is determined by anesthesia time or surgical time.

The incidence of POV was higher and significant in patients discharged to the home than in hospitalized patients $(12.63 \%$ vs. $9.47 \%$ ). The incidence of POV at home is similar to the $14 \%$ found by Efune et al. (28). This author also described variables that were associated with a higher incidence of POV at home, including, perioperative opioid administration, inhaled anesthetics and the use of opioid medications at home. The first two variables were present in the majority of patients included in this study, but home use of opioids was not assessed.

Regarding POV treatment, rescue was given to $37.5 \%$ of hospitalized patients and only to $4.17 \%$ of the patients with vomiting episodes at home. This reflects low treatment of symptoms in these patients, hence the recommendation to implement measures for follow-up, education and timely and systematic management of this postoperative complication.

This study has weaknesses derived from a sample unsuitable for finding statistically significant differences for the vast majority of the assessed variables, and a non-representative number of high risk surgeries (ophthalmological and otolaryngological). Moreover, sample size 
was calculated based on the general POV incidence reported in the literature instead of each individual risk factor.

The identification of factors associated with POV in our population will lead to adequate risk stratification and the use of appropriate risk-based prophylactic therapy. Finally, though it was not part of the study or its objective, it is time to design clinical practice guidelines focused on prevention and treatment of postoperative nausea and vomiting in the pediatric population.

\section{ETHICAL RESPONSIBILITIES}

\section{Human and animal protection.}

The authors state that the procedures were carried out in compliance with the ethical standards of the Responsible Human Experimentation Committee and in accordance with the World Medical Association and the Declaration of Helsinki.

\section{Data confidentiality}

The authors declare that they followed the protocols of their center pertaining to patient data disclosure.

\section{Right to privacy and informed consent}

The authors obtained the informed consent of the patients and/or subjects referenced in this article. The forms are kept by the corresponding author.

\section{Ethics committee approval}

This study was approved by the following two ethics committees:

1. Committee of Ethics in Scientific Research of the Universidad Industrial de Santander (CIENCI-UIS), in a meeting held on December 15, 2017, as recorded in act number 29.

2. Hospital Bioethics Committee of the
Materno Infantil San Luis Clinic, in its session of June 21, 2018, as recorded in act number DM-77-18.

\section{ACKNOWLEDGEMENTS}

\section{Authors' contributions}

MFJD y IEAT: Participated in the design and preparation of the research protocol, patient sample collection, creation of the databases, discussion of the results and drafting of the manuscript.

JADV: Participated in the design and preparation of the research protocol, patient sample collection, discussion of the results and drafting of the manuscript.

HJM: Participated in the design and preparation of the research protocol, variable analysis and processing, discussion of the results and drafting of the manuscript.

HHT: Participated in the design and preparation of the research protocol, discussion of the results and revision of the manuscript.

\section{Assistance for the study}

Anesthesia and Resuscitation Department, Universidad Industrial de Santander.

\section{Support and financial sponsorship}

This study was funded by the authors in its entirety.

\section{Conflict of interest}

None.

\section{Presentaciones}

- Research study presentation at the XXXIII Colombian Congress of Anesthesia and Resuscitation, 2019.

- Research protocol presentation at the XXIX Colombian Medical Research Student Congress (CECIM), 2018.

\section{REFERENCES}

1. Bourdaud N, Devys JM, Bientz J, Lejus C, Hebrard A, Tirel O, et al. Development and validation of a risk score to predict the probability of postoperative vomiting in pediatric patients: The VPOP score. Paediatr Anaesth. 2014;24(9):945-52. DOI: 10.1111/pan.12428

2. Sakellaris C, Georgogianaki P, Astyrakaki E, Michalakis M, Dede O, Alegakis A, et al. Prevention of post-operative nausea and vomiting in children - a prospective randomized double-blind study. Acta Paediatr. 2008;8014. DOI:10.1111/j.1651-2227.2008.00804.x

3. Elgueta MF, Echevarría CC, De La Fuente $N$, Cabrera F, Valderrama A, Cabezón R, et al. Effect of intravenous fluid therapy on postoperative vomiting in children undergoing tonsillectomy. Br J Anaesth. 2013;110(4):607-14. DOI: 10.1093/bja/aes453

4. Höhne C, Ho C. Postoperative nausea and vomiting in pediatric anesthesia. Curr Opin Anaesthesiol. 2014;27(3):303-8. DOI: 10.1097/ ACO.0000000000000073

5. Horn CC, Wallisch W], Homanics CE, Williams JP. Pathophysiological and neurochemical mechanisms of postoperative nausea and vomiting. Eur ] Pharmacol. 2014;722(1):55-66. DOI: 10.1016/j.ejphar.2013.10.037

6. Bolton CM, Myles PS, Nolan T, Sterne JA. Prophylaxis of postoperative vomiting in children undergoing tonsillectomy: A systematic review and meta-analysis. $\mathrm{Br}]$ Anaesth. 2006;97(5):593-604. DOI: 10.1093/bja/ael256

7. Carr AS, Courtman S, Holtby H, Morton N, Jacobson S, Brennan L, et al. Guidelines on the prevention of post-operative vomiting in children. Assoc Paediatr Anaesth Gt Britain Irel. 2009;35.

8. Calvache JA, León Guzmán É, Gómez Buitrago LM, García Torres C, Torres M, Buitrago $\mathrm{G}$, et al. Manual de práctica clínica basado en la evidencia: manejo de complicaciones posquirúrgicas. Colombian Journal of Anesthesiology. 2015;43(1):51-60. DOI: 10.1016/j. rca.2014.10.005

9. Gómez-Arnau JI, Aguilar JL, Bovaira P, Bustos F, De Andrés ], De La Pinta JC, et al. Recomendaciones de prevención y tratamiento de las náuseas y vómitos postoperatorios y/o asociados a las infusiones de opioides. Rev la Soc Esp del Dolor. 2011;18(1):24-42. DOI: 10.1016/ $\underline{\text { So034-9356(10)70711-8 }}$ 
10. KovacAL. Management of postoperative nausea and vomiting in children. Paediatr Drugs. 2007;9(1):47-69. DOI: 10.2165/00148581200709010-00005

11. Gan T], Diemunsch P, Habib AS, Kovac A, Kranke $P$, MeyerTA, etal. Consensus guidelines for the management of postoperative nausea and vomiting. Anesth Analg. 2014;118(1):85113. DOI: $10.1213 /$ ANE. 0000000000000002

12. Klenke S, de Vries G], Schiefer L, Seyffert N, Bachmann HS, Peters ], et al. Genetic contribution to PONV risk. Anaesth Crit Care Pain Med. 2019;(2018). DOI: 10.1016/j.accpm.2019.04.012

13. Eberhart LH], Geldner G, Kranke P, Morin AM, Schäuffelen A, Treiber H, et al. The development and validation of a risk score to predict the probability of postoperative vomiting in pediatric patients. Anesth Analg. 2004;99(6):1630-7. DOI: 10.1213/01. ANE.0000135639.57715.6C

14. Saito $\mathrm{Y}$, Kumamoto T, Arima T, Shirakawa N, Ishimaru S, Sonoda T, et al. Evaluation of aprepitant and fosaprepitant in pediatric patients. Pediatr Int. 2019;61(3):235-9. DOI: 10.1111/ ped. 13780

15. Morrison C, Wilmshurst S. Postoperative vomiting in children. BJA Educ. 2019;19(10):32933. https://doi.org/10.1016/j.bjae.2019.05.006

16. Ali U, Tsang M, Campbell F, Matava C, Igbeyi B, Balakrishnan S, et al. Reducing postoperative pain in children undergoing strabismus surgery: From bundle implementation to clinical decision support tools. Paediatr Anaesth. 2020;30:415-23. DOI: 10.1111/pan.13811

17. Eberhart LH], Morin AM, Guber D, Kretz F], Schäuffelen A, Treiber $\mathrm{H}$, et al. Applicability of risk scores for postoperative nausea and vomiting in adults to paediatric patients. $\mathrm{Br}$ ] Anaesth. 2004;93(3):386-92. DOI: 10.1093/bja/ $\underline{\text { aeh221 }}$
18. Bujang MA, Sa'At N, Tg Abu Bakar Sidik TMI, Lim C]. Sample size guidelines for logistic regression from observational studies with large population: Emphasis on the accuracy between statistics and parameters based on real life clinical data. Malaysian ] Med Sci. 2018;25(4):122-30. DOI: 10.21315/ mjms2018.25.4.12

19. Van Smeden M, Moons KGM, de Groot JAH, Collins CS, Altman DG, Eijkemans MJC, et al. Sample size for binary logistic prediction models: Beyond events per variable criteria. Stat Methods Med Res. 2019;28(8):2455-74. DOI: $\underline{10.1177 / 0962280218784726}$

20. Van Diepen M, Ramspek CL, Jager K], Zoccali C, Dekker FW. Prediction versus aetiology: Common pitfalls and how to avoid them. Nephrol Dial Transplant. 2017;32(February):I11-5. DOI: 10.1093/ndt/gfw459

21. Ashok V, Bala I, Bharti N, Jain D, Samujh R. Effects of intraoperative liberal fluid therapy on postoperative nausea and vomiting in children-A randomized controlled trial. Paediatr Anaesth. 2017;27(8):810-5. DOI: 10.1111/ pan.13179

22. Braitman LE. Confidence intervals assess both clinical significance and statistical significance. Ann Intern Med. 1991;114(6):515-7. DOI: $10.7326 / 0003-4819-114-6-515$

23. Argimon Pallas JJVJ. Métodos de investigación clínica y epidemiológica. Segunda ed. Madrid: Ediciones Harcourt; 2000.

24. Frelich $M$, Divák ], Vodička V, Masárová $M$, Jor O, Gál R. Dexamethasone reduces the incidence of postoperative nausea and vomiting in children undergoing endoscopic adenoidectomy under general anesthesia without increasing the risk of postoperative hemorrhage. Med Sci Monit. 2018;24:8430-8. DOI: 10.12659/MSM.911231

25. Czarnetzki C, Lysakowski C, Dumont L, Landis BN, Giger R, Desmeules ]. Dexamethasone and risk of nausea and vomiting and postoperative bleeding after tonsillectomy in children. JAMA. 2015;300(22):2621-30. DOI: 10.1001/jama.2008.794

26. Mehrotra S. Postoperative anaesthetic concerns in children: Postoperative pain, emergence delirium and postoperative nausea and vomiting. Indian ] Anaesth. 2019;63(9):763-70. DOI: $10.4103 /$ ija.IJA

27. Schaefer MS, Kranke P, Weibel S, Kreysing R, Ochel ], Kienbaum P. Total intravenous anesthesia vs single pharmacological prophylaxis to prevent postoperative vomiting in children: A systematic review and meta-analysis. Paediatr Anaesth. 2017;27(12):1202-9. DOI: 10.1111/pan.13268

28. Efune PN, Minhajuddin A, Szmuk P. Incidence and factors contributing to postdischarge nausea and vomiting in pediatric ambulatory surgical cases. Paediatr Anaesth. 2018;28(3):257-63. DOI: 10.1111/pan.13333

29. Sinclair DR, Chung F, Mezei C. Can postoperative nausea and vomiting be predicted? Anesthesiology. 1999;91(1):109-18. DOI: $\underline{10.1097 / 00000542-199907000-00018}$

30. Kocaturk O, Keles S, Omurlu IK. Risk factors for postoperative nausea and vomiting in pediatric patients undergoing ambulatory dental treatment. Niger ] Clin Pract. 2018;21(5):597602. DOI: 10.4103/njcp.njcp_129_17 